\title{
ESTUdO DAS ÁREAS DE PROTEÇÃo PERMANENTE DO RIO PARAÍ́BA DO SUL NO MUNICÍPIO DE CAMPOS DOS GOYTACAZES - RJ
}

\author{
Zélia Maria Peixoto Chrispim $^{1 *}$, Camille Pereira de Oliveira ${ }^{1}$, Jhonny Lacerda ${ }^{1}$ \& Ronaldo \\ de Sousa Araújo ${ }^{2}$
}

\section{RESUMO}

CHRISPIM, Z.M.P.; OLIVEIRA, C.P.; LACERDA, J.; ARAÚJO, R.S. Estudo das Áreas de Proteção Permanente do Rio Paraíba do Sul no Município de Campos dos Goytacazes - RJ. Perspectivas Online: Exatas \& Engenharia, v.10, n. 28, p. 54-68, 2020.

A pesquisa realizada teve como foco o estudo das áreas de mata ciliar no entorno do Rio Paraíba do Sul no município de Campos dos Goytacazes - RJ. Foi seguido o novo Código Florestal (Lei $\mathrm{n}^{\circ}$ 12.651/2012) para a delimitação das margens dos cursos d'água para Áreas de Preservação Permanente (APPs). O objetivo da pesquisa foi verificar a situação atual dessas áreas à luz da legislação pertinente, tendo como parâmetro a disponibilidade de água em quantidade e qualidade. Quanto à metodologia foram realizadas as seguintes etapas: coleta de dados bibliográficos e documentais, como artigos, mapas, leis, imagens de satélite; revisão bibliográfica; quantificação das
APPs; elaboração de gráficos; geração de mapa. Espera-se com esta pesquisa disponibilizar dados para contribuir com o planejamento e a gestão de recursos hídricos da região, garantindo assim a preservação das matas ciliares e o acesso aos diferentes usos da água. Verificou-se no estudo um grande distanciamento da quantidade de mata ciliar existente nas margens do rio Paraíba do Sul no município de Campos dos Goytacazes (apenas 9,20\%), e a quantidade exigida pela lei federal. É necessário que se busquem medidas sustentáveis para a solução do problema do conflito entre as atividades agropecuárias e as necessidades ambientais regulamentadas em lei.

Palavras-chave: Recursos Hídricos; Mata Ciliar; Código Florestal; APPs.

\footnotetext{
${ }^{1}$ Laboratório de Estudos em Estratégia, Gestão e Inovação (LEEGI), Institutos Superiores de Ensino do CENSA (ISECENSA) - Rua Salvador Correa, 139, Centro, Campos dos Goytacazes, RJ, CEP: 28035-310, Brasil.

${ }^{2}$ Laboratório de Estudos Urbanos e Ambientais (LEUA), ISECENSA - Rua Salvador Correa, 139, Centro, Campos dos Goytacazes, RJ, CEP: 28035-310, Brasil.

(*) e-mail: zeliachrispim.100@gmail.com
} 


\title{
STUDY OF THE PERMANENT PROTECTION AREAS OF THE PARAÍBA DO SUL
} RIVER IN THE MUNICIPALITY OF CAMPOS DOS GOYTACAZES - RJ

\author{
Zélia Maria Peixoto Chrispim ${ }^{1 *}$, Camille Pereira de Oliveira ${ }^{1}$, Jhonny Lacerda ${ }^{1}$ \& Ronaldo \\ de Sousa Araújo ${ }^{2}$
}

\begin{abstract}
CHRISPIM, Z.M.P.; OLIVEIRA, C.P.; LACERDA, J.; ARAÚJO, R.S. Study of the permanent protection areas of the paraíba do sul river in the municipality of Campos dos Goytacazes - RJ (In Portuguese). Perspectivas Online: Exatas \& Engenharia, v. 10, n. 28, p. 54-68, 2020.
\end{abstract}

The research carried out focused on the study of riparian forest areas around the Paraíba do Sul River in the municipality of Campos dos Goytacazes - RJ. The new Forest Code (Law number 12.651 / 2012) was followed to define the margins of watercourses for Permanent Preservation Areas (APPs). The objective of the research was to verify the current situation of these areas in the light of the relevant legislation, taking as a parameter the availability of water in quantity and quality. Regarding the methodology, the following steps were performed: collection of bibliographic and documentary data, such as articles, maps, laws, satellite images; literature review; quantification of
APPs; elaboration of graphs; map generation. This research is expected to provide data to contribute to the planning and management of water resources in the region, thus ensuring the preservation of riparian forests and access to different uses of water. In the study, there was a relevant deviation between the amount of riparian forest on the banks of the Paraíba do Sul river in the municipality of Campos dos Goytacazes (only 9,20\%) and the amount required by the federal legislation. It is necessary to seek sustainable measures to solve the problem of conflict between agricultural activities and environmental needs regulated by law.

Keywords: Water Resources; Riparian forest; Forest Code; APPs.

\footnotetext{
${ }^{1}$ Laboratório de Estudos em Estratégia, Gestão e Inovação (LEEGI), Institutos Superiores de Ensino do Censa (ISECENSA).Rua Salvador Correa, 139, Centro, Campos dos Goytacazes, RJ, CEP: 28035-310, Brasil.

${ }^{2}$ Laboratório de Estudos Urbanos e Ambientais (LEUA), ISECENSA - Rua Salvador Correa, 139, Centro, Campos dos Goytacazes, RJ, CEP: 28035-310, Brasil.

(*) e-mail: zeliachrispim.100@gmail.com
} 


\section{INTRODUÇÃO}

A água é um recurso mineral que tem apresentado grande foco de interesse pelos mais diversos setores, sobretudo pelo entendimento de que é um recurso limitado em termos de qualidade e quantidade. A legislação sobre o assunto é abrangente e muitos são os desafios de gestão, destaca-se a deficiência no controle e monitoramento, e a falta de integração com o âmbito florestal (ARAÚJO et al., 2015). As leis e normas que são aplicáveis à gestão de recursos hídricos no Brasil, se forem aplicadas de forma coesa e coletiva, poderão contribuir com a gestão, distribuição e manutenção da água (SOUZA; PERTEL, 2020).

Comparado com outros países, o Brasil apresenta abundância de água doce. No entanto, a grande diversidade de riscos relacionados com essa fonte hídrica resulta em incerteza na disponibilidade deste recurso para a população. Ademais, os desafios relacionados à agua estão relacionados com inúmeros efeitos no meio ambiente e na economia (MOREIRA, 2019). Cada vez é maior a demanda dos recursos hídricos, no entanto a água superficial é cada vez mais escassa e com menor qualidade, isso tem ampliado de forma significativa o uso das águas subterrâneas (CHRISPIM et al., 2018).

A água é um recurso considerado renovável, porque depois de sua utilização fica disponível novamente, isso ocorre devido aos ciclos naturais. O processo de utilização antrópica da água resulta no surgimento da poluição. As fontes poluidoras podem ser naturais ou antrópicas. Atividades humanas geram resíduos que causam impacto ambiental negativo. Assim, a poluição está vinculada à concentração, ou quantidade, de resíduos existentes na água (BRAGA et al., 2012). Vale resaltar, que o ciclo natural da água pode ser prejudicado se o ambiente estiver poluído e/ou contaminado, pois neste caso a reciclagem deverá ocorrer mais lentamente.

Moss (2014) destaca que graças aos estudos realizados por pesquisadores tanto no Brasil como em outros países, as florestas têm uma correlação direta com a quantidade e qualidade de água disponível para a população. Graziano Neto (2009) ainda ressalta que matas e água são inseparáveis. A vegetação tem uma ligação direta com a permeabilidade dos solos, sendo considerada determinante para a regularização de vazão dos rios. Esta relação é evidenciada pela vegetação que delimita os cursos d'água, no caso a mata ciliar, que desempenha a função de estabilização das margens dos recursos hídricos, desacelerando desta forma o processo de erosão e de assoreamento. Contudo, a legislação ainda trata os temas água e floresta de forma separada (ARAÚJO et al., 2015). Na Europa, as florestas já ocuparam cerca de $80 \%$ de seu território. No final do século VII mais da métade deste ecossistema havia desaparecido (EEA, 2020). Hoje, o continente busca uma transição entre o desmatamento e o reflorestamento (MATHER, 2001).

As florestas também estão no centro das atenções ambientais quando o assunto é o clima e a qualidade do ar. Ao remover uma floresta, são eliminadas plantas que tirariam carbono da atmosfera à medida que crescem (RIEBEEK, 2011). Lawrence e Vandecar (2014) realizaram estudo dos efeitos do desmatamento de regiões tropicais no clima e na agrigultura, indicando condições mais quentes e mais secas em escala local, que afetam a produção agrícola. Lacerda et al. (2009) realizaram estudo de quantificação da captura e armazenamento de $\mathrm{CO} 2$ em uma área restaurada com plantio de espécies nativas. Os resultados apresentados demonstraram $7,0 \mathrm{~kg}$ de $\mathrm{CO} 2$-equivalente ao ano ou 140,0 $\mathrm{kg}$ de CO2-equivalente por árvore em 20 anos, ou ainda 7,14 árvores por tonelada (t) de

Persp. Online: exatas \& eng., Campos dos Goytacazes, 28 (10) $54-68$ - 2020 
$\mathrm{CO}_{2}$-equivalente em 20 anos (CO2-equivalente é uma unidade que representa gases do efeito estufa).

Kunkle (1974 apud ZAKIA, 1998) enfatiza que a mata ciliar abrange as áreas mais sensíveis da bacia, ou seja, situa-se às margens da rede hidrográfica, ao redor de nascentes e em áreas saturadas, exercendo influência direta na hidrologia da bacia. De acordo com Castro et al. (2012) as matas ciliares são importantes por proporcionarem um conjunto de funções ecológicas indispensáveis para a qualidade de vida especialmente das populações locais e da bacia hidrográfica, sendo fundamentais para a conservação da diversidade da fauna e da flora da região nativa, tanto terrestres como aquáticas.

Medeiros (2013) observa que são várias as denominações atribuídas à vegetação natural nas margens dos cursos d'água, destaca-se floresta ciliar, aquela que se entende como mata ciliar, outra denominação, floresta ou mata de galeria.

Segundo a Lei 12.651 conhecida como "Novo Código Florestal", artigo 3º, inciso II:

Área de Preservação Permanente - APP: área protegida, coberta ou não por vegetação nativa, com a função ambiental de preservar os recursos hídricos, a paisagem, a estabilidade geológica e a biodiversidade, facilitar o fluxo gênico de fauna e flora, proteger o solo e assegurar o bem-estar das populações humanas. (BRASIL, 2012).

E em relação à delimitação das APPs a lei em seu artigo $4^{\circ}$ estabelece:

(I) as faixas marginais de qualquer curso d'água natural perene e intermitente, excluídos os efêmeros, desde a borda da calha do leito regular; [...]"; d) 200 (duzentos) metros, para os cursos d'água que tenham de 200 (duzentos) a 600 (seiscentos) metros de largura; e) 500 (quinhentos) metros, para os cursos d'água que tenham largura superior a 600 (seiscentos) metros (BRASIL, 2012).

O município de Campos dos Goytacazes apresenta certa vulnerabilidade em termos de abastecimento público, pois este é realizado pela captação no Rio Paraíba do Sul, que pode ser contaminado a qualquer momento, devido a grande quantidade de áreas urbanizadas e indústrias existentes no seu percurso. Essa preocupação é relevante, pois isso já ocorreu durante o desastre de rompimento da barragem em Cataguases-MG, ocorrido em 29 de março de 2003, quando o derrame de um grande volume de substâncias tóxicas (poluição aguda) deixou a população sem água (ALVES et al., 2010). Assim, é importante salientar o papel da vegetação nas margens do rio, para resiliência do recurso e disponibilidade em qualidade e quantidade. Chrispim (2016) observa que a diminuição da vazão do rio pode influenciar no nível freático das águas subterrâneas e superficiais.

No município, o Plano Diretor é o instrumento básico da política de desenvolvimento e de expansão urbana. Ele contém normas e diretrizes sobre o sistema viário, o zoneamento e os espaços verdes. "O regime jurídico das áreas verdes pode incidir sobre espaços públicos e privados", visando à preservação para fins de recreação e equilíbrio ambiental. (SILVA, 2015).

Persp. Online: exatas \& eng., Campos dos Goytacazes, 28 (10) $54-68$ - 2020 
Araújo et al. (2019) estudaram a execução do plano diretor de Campos dos Goytacazes, no período 2008-2018, nos aspectos sistema viário, zoneamento e áreas verdes. Em muitas áreas verdes pesquisadas foram observadas ocupações contrárias ao planejamento. Ocupações que demonstram conflitos de interesses individuais e coletivos, de ocupação do solo contrariando o interesse público de preservação ambiental.

O atual Plano Diretor de Campos dos Goytacazes, Lei Complementar n ${ }^{\circ}$ 0015/2020, em seu Artigo 66, dispõe que para a criação, proteção e recuperação de Unidades de Conservação, deverão ser executadas entre outras medidas: "VII. Recuperar a vegetação ciliar do rio Paraíba do Sul, dando à área uso compatível com a preservação ambiental". E para a conservação, proteção e recuperação de vegetação nativa, o Plano Diretor, Art. 67, dispõe sobre a necessidade de: "II. Reflorestar as matas ciliares com espécies nativas". (CAMPOS DOS GOYTACAZES, 2020).

Para assegurar a manutenção da quantidade e qualidade dos recursos hídricos na região do município de Campos dos Goytacazes, de uma maneira sustentável, existe a necessidade de estudos e monitoramento das faixas constituintes das APPs, especialmente do Rio Paraíba do Sul. Este trabalho tem como foco o estudo das áreas de mata ciliar ao longo do Rio Paraíba do Sul (APPs a montante e a jusante do distrito sede) no município de Campos dos Goytacazes - RJ (Figura 1).

O objetivo principal da pesquisa foi verificar a situação atual das Áreas de Preservação Permanentes - APPs à luz do novo Código Florestal (Lei n. ${ }^{\circ}$ 12.651/2012). Quanto aos objetivos específicos: mapear as áreas de matas ciliares ao longo das faixas de preservação do Rio Paraíba do Sul, obedecendo a delimitação estabelecida pela legislação; quantificar em porcentagem as áreas com e sem matas ciliares.

\section{MATERIAIS E MÉTODOS}

Esta pesquisa foi desenvolvida nas instalações dos Institutos Superiores de Ensino do Censa - ISECENSA / LEEGI - Laboratório de Estudos em Estratégia, Gestão e Inovação / LEUA - Laboratório de Estudos Urbanos e Ambientais. A metodologia empregada nesta pesquisa foi desenvolvida com as seguintes etapas:

- Levantamento de dados bibliográficos e documentais: artigos, dissertações, teses, leis, normas, arquivos de shapefile, mapas etc.;

- Tratamento dos dados levantados;

- Utilização de imagens de satélite (Landasat / Copernicus) do programa Google Earth Pro para produção de figuras, em que foram delimitadas e quantificadas as áreas de APPs ao longo do rio Paraíba do Sul, assim como as áreas de mata ciliar por trechos a montante e a jusante do distrito sede de Campos dos Goytacazes, seguindo as disposições do Código Florestal, Lei no 12.651/2012;

- Elaboração de gráficos com a utilização do software Excel, com a quantificação em porcentagem das áreas com e sem vegetação de floresta.

Persp. Online: exatas \& eng., Campos dos Goytacazes, 28 (10) $54-68-2020$

https://ojs3.perspectivasonline.com.br/ 


\section{RESULTADOS}

A pesquisa desenvolveu-se em duas regiões ao longo das Áreas de Preservação Permanente (APPs) do rio Paraíba do Sul no município de Campos dos Goytacazes. As áreas objeto de estudo abrangem as regiões a montante e a jusante da zona urbanizada do distrito sede da cidade.

Na figura 1 pode-se observar a região a montante (lado esquerdo) e região a jusante (lado direito) estudadas neste trabalho. Observa-se também na figura, à direita, a foz do rio Paraíba do Sul e um trecho de APP no município de São João da Barra, que não fizeram parte deste estudo.

A abrangência das APPs e seus limites demarcados levaram em consideração as disposições da Lei $\mathrm{N}^{\circ}$ 12.651/2012, Código Florestal Brasileiro (BRASIL, 2012), em seu artigo $4^{\circ}: 200$ (duzentos) metros, para os cursos d'água que tenham de 200 (duzentos) a 600 (seiscentos) metros de largura, e 500 (quinhentos) metros, para os cursos d'água que tenham largura superior a 600 (seiscentos) metros.

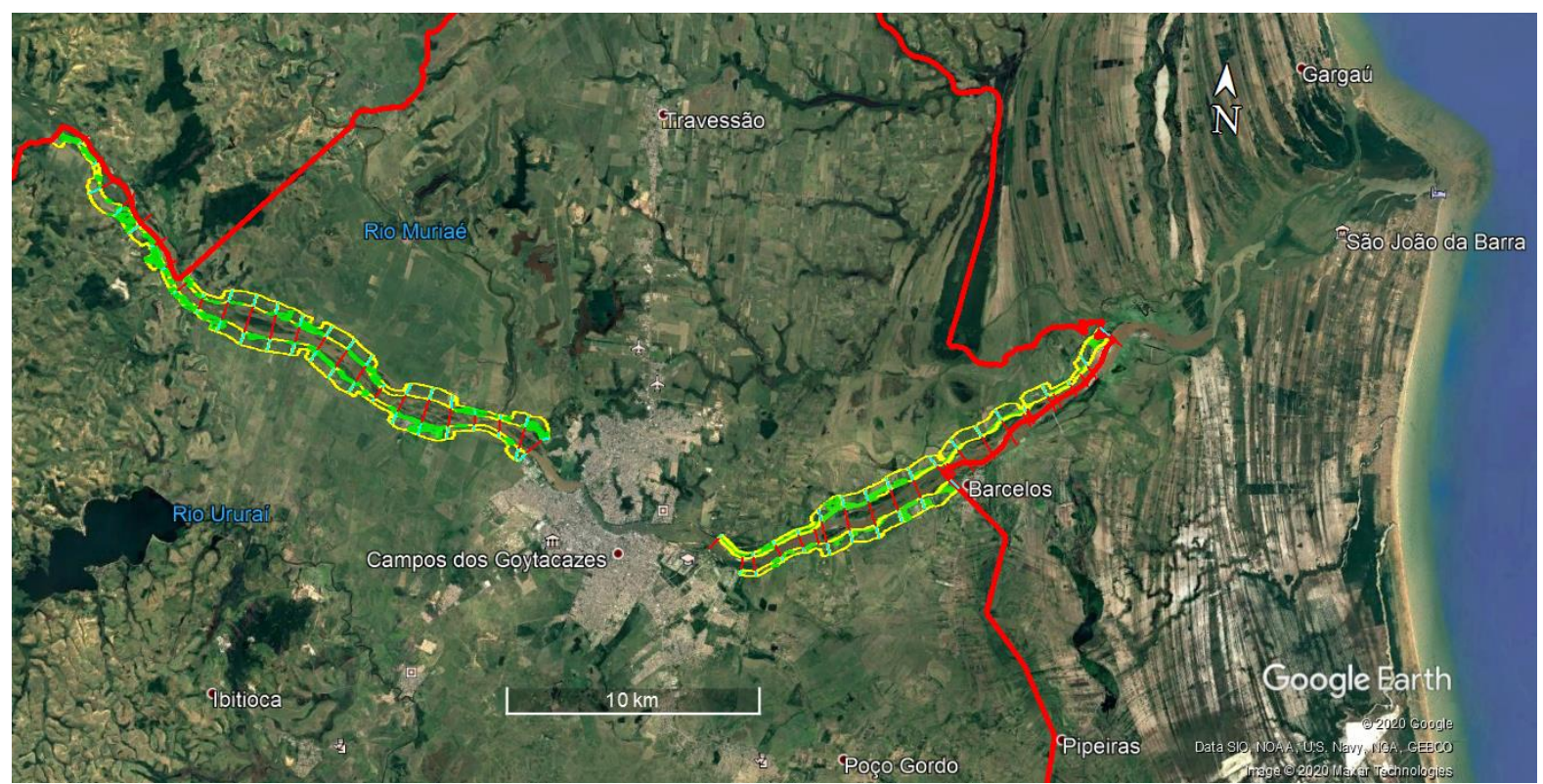

Figura 1 - Área total estudada no município de Campos dos Goytacazes, RJ. Linha vermelha continua: limite do município de Campos dos Goytacazes. Linha amarela: limites das APPs. Linha Verde: matas ciliares preservadas. Fonte: Google Earth com edição dos autores, 2020.

O estudo realizado nas Áreas de Preservação Permanente (APPs) ao longo do rio Paraíba do Sul, a montante e a jusante do distrito sede de Campos dos Goytacazes, resultou na quantificação das áreas com e sem mata ciliar nestas faixas estabelecidas pela legislação. $\mathrm{O}$ gráfico da situação das áreas de APPs (Figura 2) apresenta a quantificação do total de mata ciliar existente nas duas regiões pesquisadas. No total foram analisadas $25.845 .924,00 \mathrm{~m}^{2}$ $(100 \%)$ de APPs, em que verificou-se 2.376.694,00 $\mathrm{m}^{2}(9,20 \%)$ de mata ciliar e 23.469.230,00 $\mathrm{m}^{2}(90,80 \%)$ de áreas sem mata.

Persp. Online: exatas \& eng., Campos dos Goytacazes, 28 (10) $54-68-2020$

https://ojs3.perspectivasonline.com.br/ 


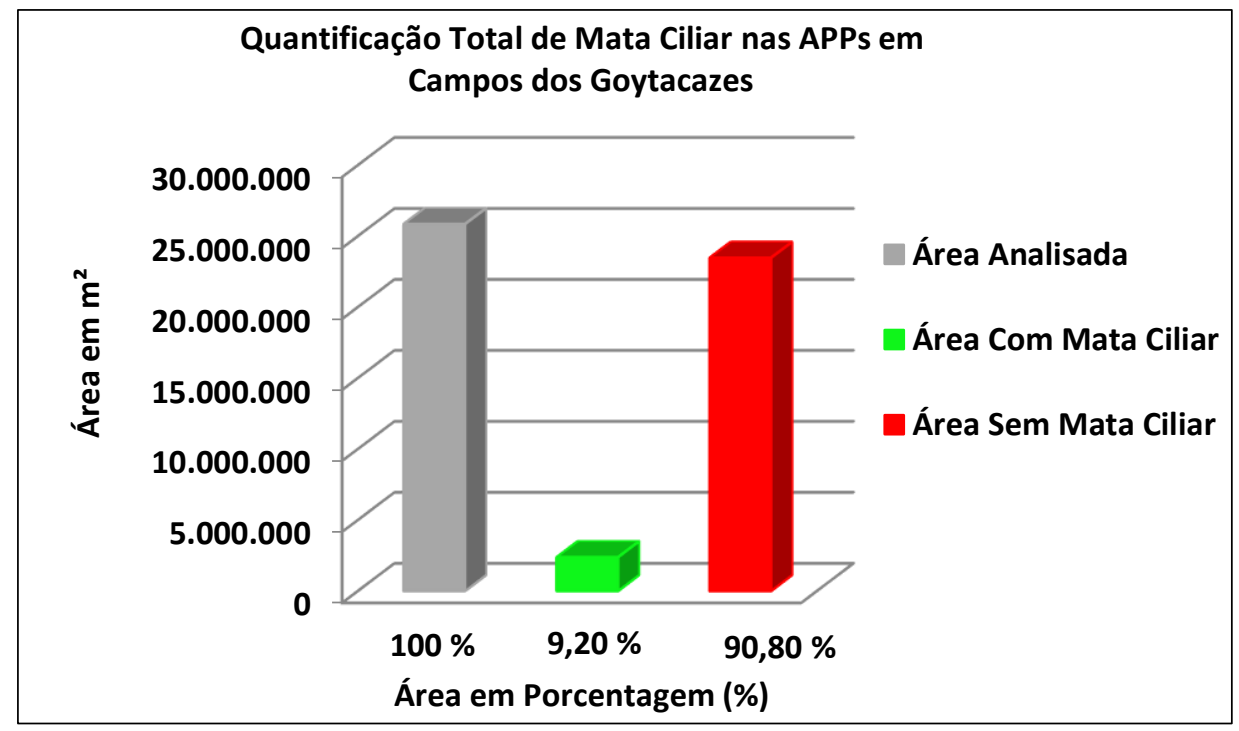

Fígura 2 - Total de áreas com e sem mata ciliar nas APPs do rio Paraíba do Sul no município de Campos dos Goytacazes, RJ.

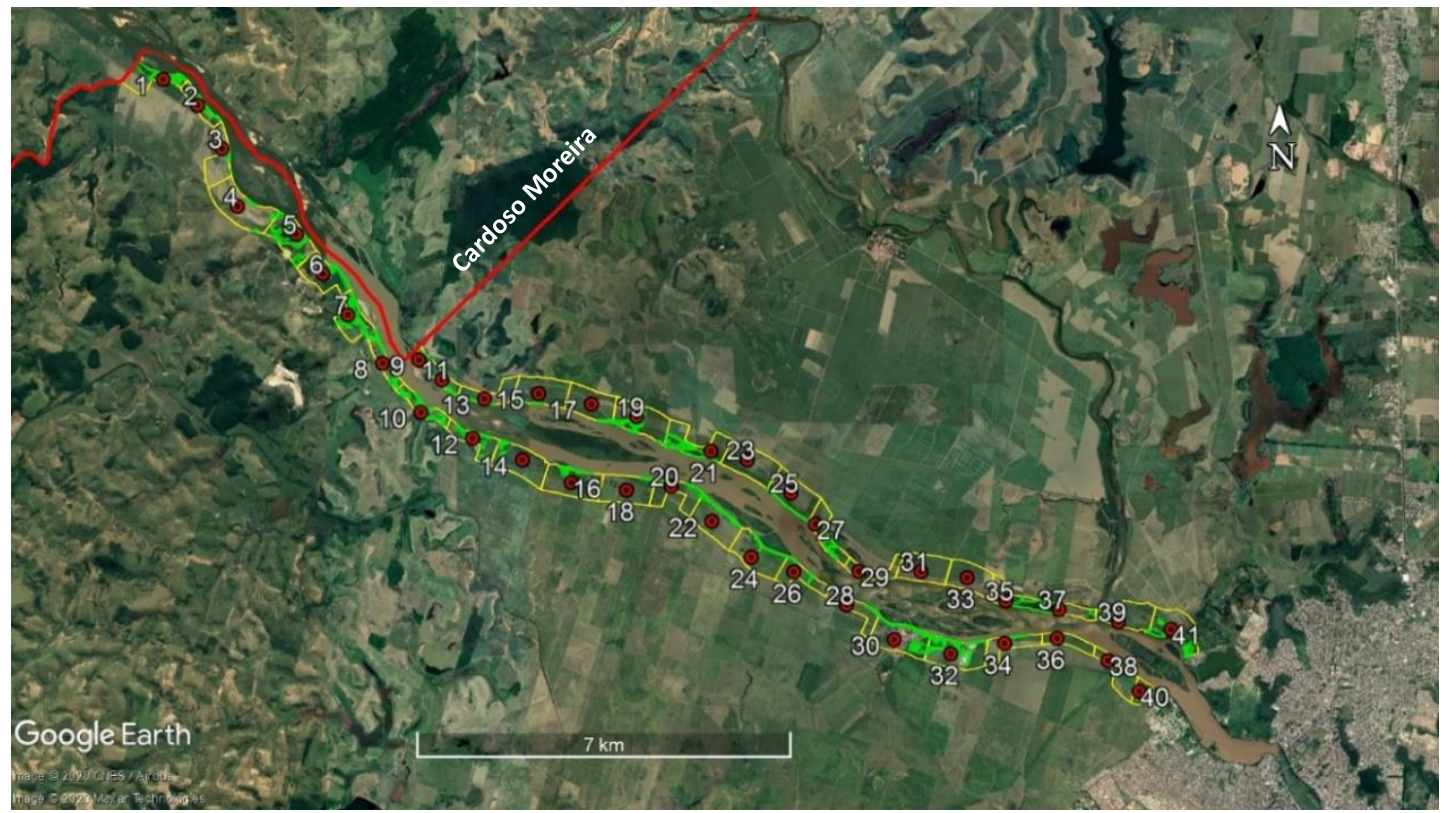

Figura 3 - Área estudada a montante da cidade de Campos dos Goytacazes, RJ. Linha vermelha continua: limite do município de Campos dos Goytacazes. Linha amarela: limites das APPs. Linha Verde: matas ciliares preservadas. Números: trechos de APPs estudadas. Fonte: Google Earth Pro com edição dos autores, 2020.

Persp. Online: exatas \& eng., Campos dos Goytacazes, 28 (10) $54-68$ - 2020 https://ojs3.perspectivasonline.com.br/ 


\section{Região a Montante}

O estudo da região do rio Paraíba o Sul localizada a montante da área urbanizada de Campos dos Goytacazes (Figura 3) foi dividida por trechos para o levantamento, em que foram calculadas as áreas com e sem matas ciliares. A região a montante foi dividida em 41 trechos considerando os dois lados do rio. Os primeiros trechos analisados foram apenas do lado direito do rio pois o outro lado pertence a outro município, no caso Cardoso Moreira.

O Trecho 1 (Figura 4) abrange duas situações de preservação da APP, uma parte com afastamento de $500 \mathrm{~m}$ e outra de $200 \mathrm{~m}$, considerando as larguras do rio Paraíba do Sul e as disposições do Código Florestal. Neste trecho a APP corresponde a $323.835 \mathrm{~m}^{2}$, onde 73.752 $\mathrm{m}^{2}(22,77 \%)$ correspondem às áreas de mata ciliar (M1; M2), e $250.083 \mathrm{~m}^{2}(77,23 \%)$ são áreas sem mata. Verifica-se que a parte mais larga do trecho é cortada por uma obra de infraestutura, no caso uma rodovia. Nota-se também outra interferência antrópica onde se vê a supressão da mata ciliar por cultura agrícola (lado direito da M2).

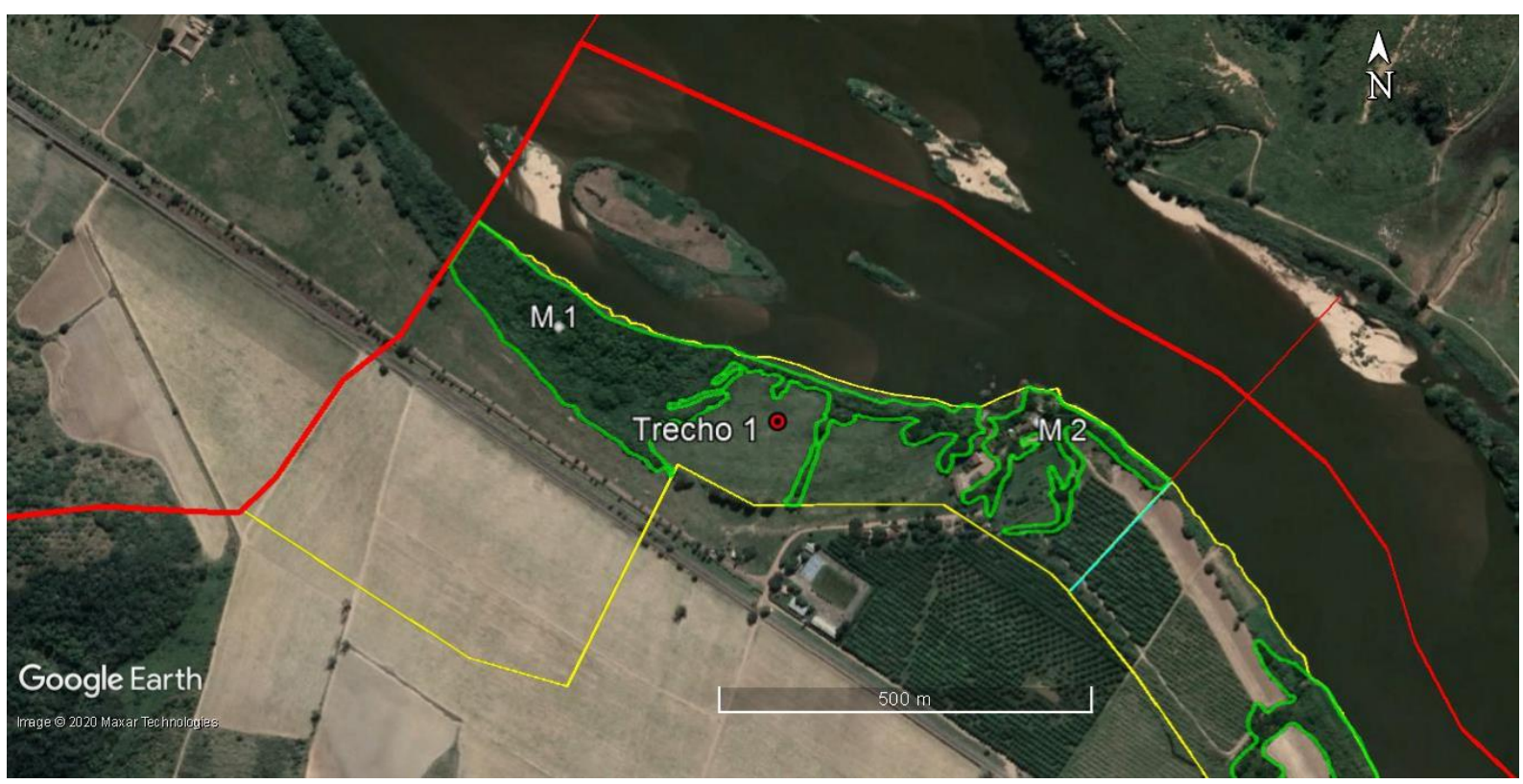

Figura 4 - Trecho 1 a montante do distrito sede de Campos dos Goytacazes. Linha vermelha continua: limite do município de Campos dos Goytacazes. Linha amarela: limites das APPs. Linha Verde: matas ciliares preservadas. Fonte: Google Earth Pro com edição dos autores, 2020.

Outro exemplo bastante significativo é o Trecho 4 (Figura 5) em que se observa uma quantidade muito reduzida de áreas de mata ciliar (M6; M7; M8; M9; M10). Neste trecho de $648.099 \mathrm{~m}^{2}$, apenas $11.797 \mathrm{~m}^{2}(1,82 \%)$ são de mata ciliar, o restante de $636.302 \mathrm{~m}^{2}(98,18 \%)$ corresponde a áreas sem mata. 


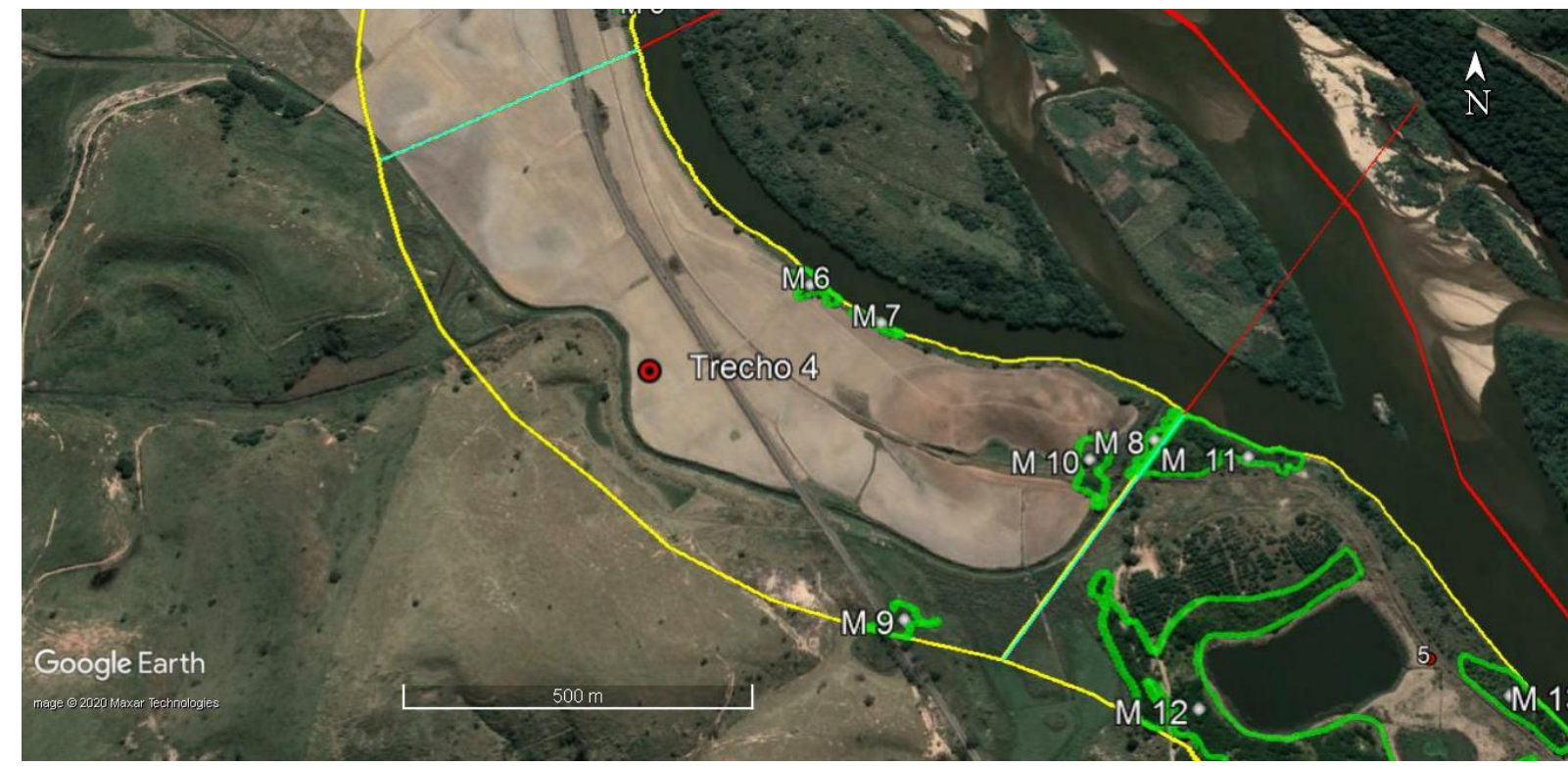

Figura 5 - Trecho 4 a montante do distrito sede de Campos dos Goytacazes. Linha vermelha continua: limite do município de Campos dos Goytacazes. Linha amarela: limites das APPs. Linha Verde: matas ciliares preservadas. Fonte: Google Earth Pro com edição dos autores, 2020.

$\mathrm{Na}$ região do rio Paraíba do Sul a montante do Distrito Sede de Campos dos Goytacazes as áreas de APPs demarcadas e analisadas correspondem a um total de 15.054.385,00 $\mathrm{m}^{2}(100 \%)$. As áreas de mata existentes nesta região são de $1.166 .829,00 \mathrm{~m}^{2}$ $(7,75 \%)$. O restante de $13.887 .556,00 \mathrm{~m}^{2}(92,25 \%)$ corresponde às áreas desprovidas de mata ciliar ao longo do rio. No gráfico de vegetação das APPs a montante (Figura 6) verifica-se esta grande diferença das áreas com mata e sem mata ciliar.

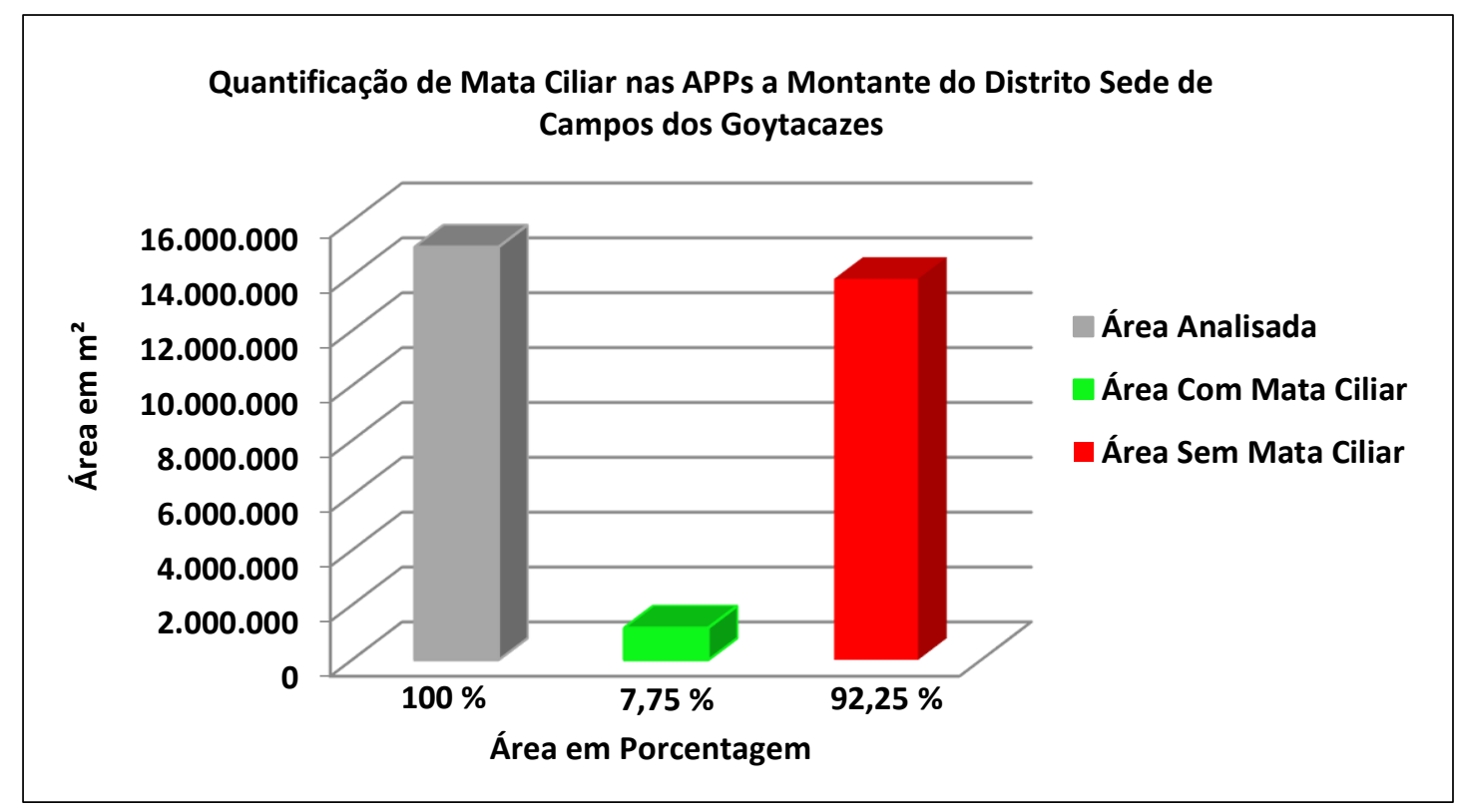

Figura 6 - Situação das matas ciliares nas APPs a montante do Distrito Sede de Campos dos Goytacazes.

Persp. Online: exatas \& eng., Campos dos Goytacazes, 28 (10) $54-68$ - 2020

https://ojs3.perspectivasonline.com.br/ 


\section{Região a Jusante}

A jusante do Distrito Sede de Campos dos Goytacazes (Figura 7) os trechos foram numerados de 42 a 67 . Grande parte das APPs do lado direito do rio pertence ao município de São João da Barra, portanto não fazem parte da pesquisa.

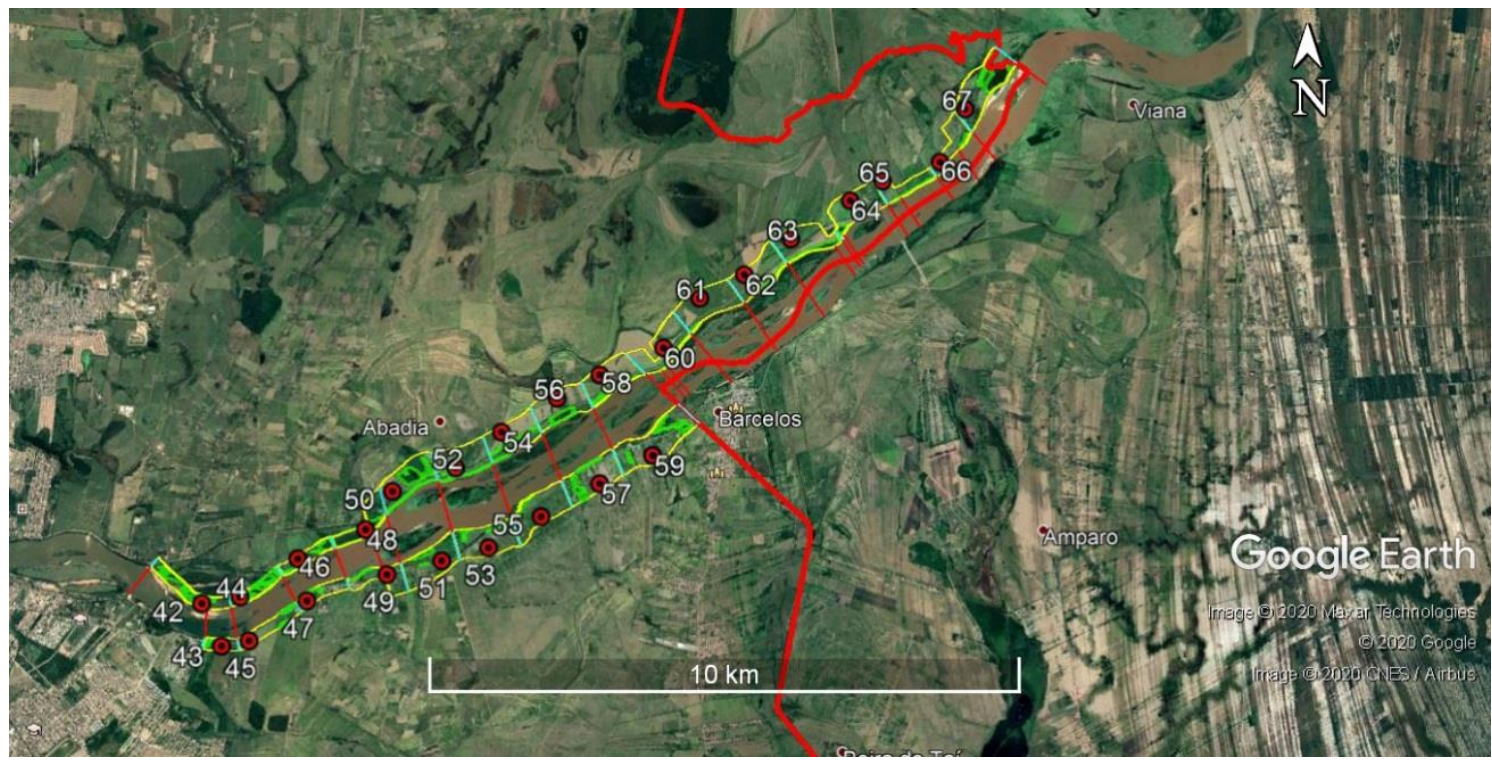

Figura 7 - Área estudada a Jusante do distrito sede de Campos dos Goytacazes. Linha vermelha continua: limite do município de Campos dos Goytacazes. Linha amarela: limites das APPs. Linha Verde: matas ciliares preservadas. Números: trechos de APPs estudadas. Fonte: Google Earth Pro com edição dos autores, 2020.

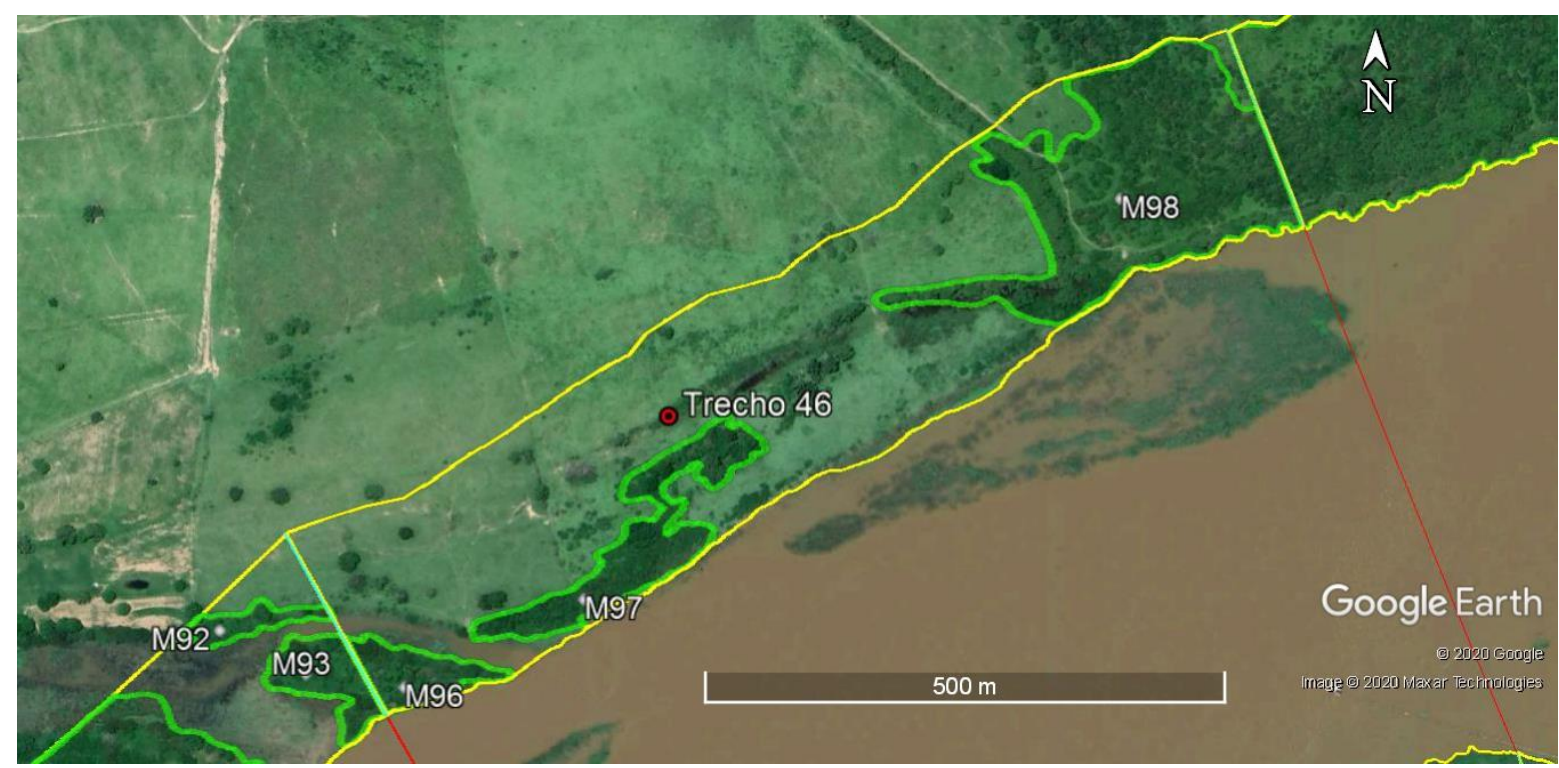

Figura 8 - Trecho 46 a jusante do distrito sede de Campos dos Goytacazes. Linha amarela: limites das APPs. Linha Verde: matas ciliares preservadas. Fonte: Google Earth Pro com edição dos autores, 2020.

O techo 46 a jusante (Figura 8) está em uma região com características mais rurais,

Persp. Online: exatas \& eng., Campos dos Goytacazes, 28 (10) $54-68-2020$

https://ojs3.perspectivasonline.com.br/ 
onde não se encontram obras de infraestrutura como em outros trechos. É um trecho cuja APP de 202.570,00 $\mathrm{m}^{2}$ tem $200 \mathrm{~m}$ de largura devido à exigência do Código Florestal neste local. As áreas de mata ciliar (M96; M97; M98) correspondem a 67.372,00 m² (33,26\%) e as sem mata a $135.198,00 \mathrm{~m}^{2}(66,74 \%)$.

O Trecho 53 (Figura 9) com 523.430,00 m², que também está bastante desprovido de mata ciliar, é cortado em toda sua extensão por uma obra de infraestrutura, a rodovia que liga a cidade de Campos dos Goytacazes a São João da Barra, sendo também a principal estrada de acesso ao Porto do Açu. Neste trecho 26.786,00 m² (5,12 \%) são de mata ciliar e 496.644,00 $\mathrm{m}^{2}(94,88 \%)$ não tem a presença de mata.

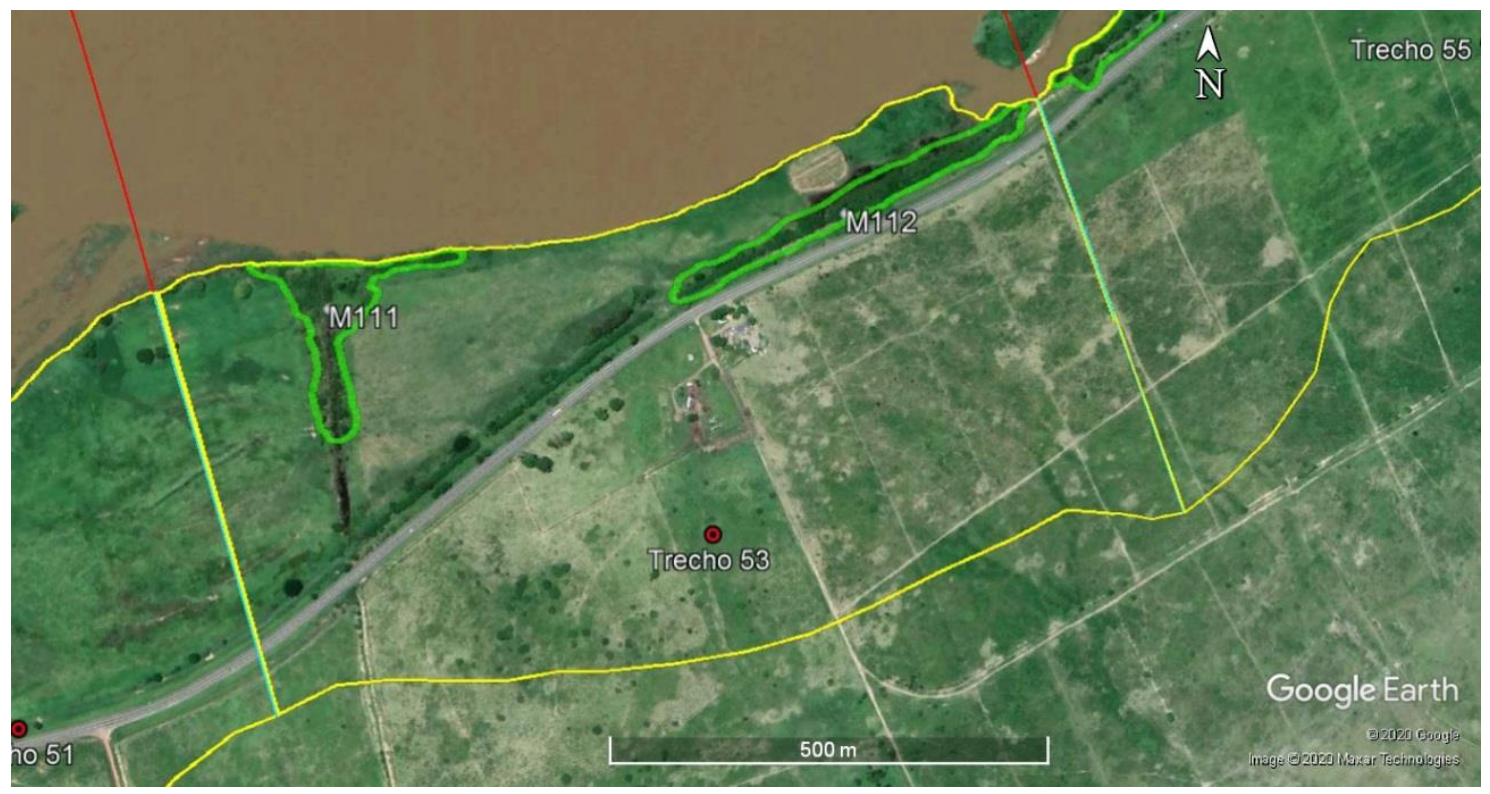

Figura 9 - Trecho 53 a jusante do distrito sede de Campos dos Goytacazes. Linha amarela: limites das APPs. Linha Verde: matas ciliares preservadas. Fonte: Google Earth Pro com edição dos autores, 2020.

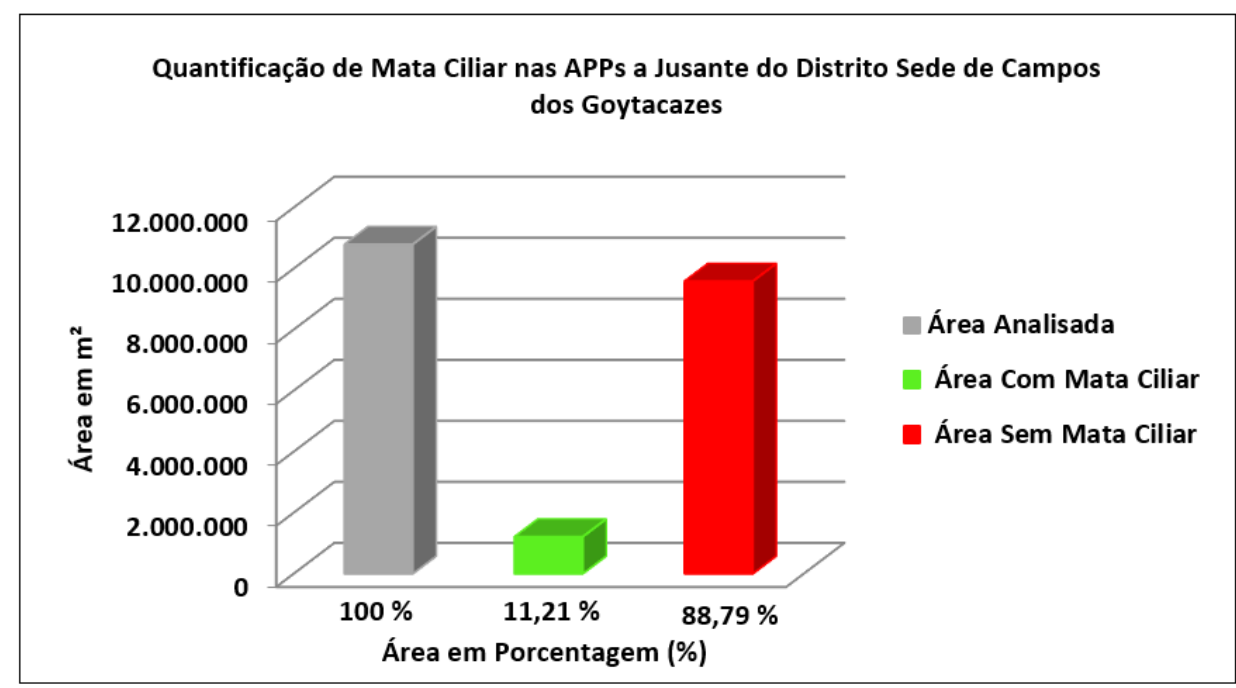

Figura 10 - Situação das matas ciliares nas APPs a Jusante do Distrito Sede do Município de Campos dos Goytacazes.

Persp. Online: exatas \& eng., Campos dos Goytacazes, 28 (10) $54-68$ - 2020

https://ojs3.perspectivasonline.com.br/ 
As APPs a jusante correspondem a 10.791.539,00 $\mathrm{m}^{2}$. Destas, $1.209 .865,00 \mathrm{~m}^{2}$ $(11,21 \%)$ são de áreas com mata ciliar. O restante, de 9.581.674,00 $\mathrm{m}^{2}(88,79 \%)$, corresponde às áreas desprovidas de mata ciliar ao longo do rio. No gráfico de matas ciliares nas APPs a jusante (Figura 10) nota-se, como na região a montante, uma grande diferença das áreas com mata e sem mata ciliar.

\section{DISCUSSÃO}

Verificou-se com os estudos que a supressão de mata ciliar ao longo do rio Paraíba do Sul aconteceram para o desenvolvimento de atividades agropecuárias e para a realização de obras de infraestrutura, como estradas, ou construção de edificações. No entanto, Graziano Neto (2009), Araújo et al. (2015), entre outros autores, observam a importância da mata ciliar no controle de erosões e assoreamentos. Muitas são as funções ecológicas dos rios, como a conservação da diversidade da fauna e da flora da região nativa, citado por Castro et al. (2012), que poderiam proporcionar melhor qualidade de vida para as populações dessas localidades. O desmatamento das matas ciliares não é exclusiva do rio Paraíba do Sul. O rio São Francisco, que nasce em Minas Gerais e passa por outros quatro estados (Bahia, Pernambuco, Sergipe e Alagoas), é outro grande rio brasileiro que também sofre com a devastação das matas ciliares, e a falta de fiscalização agrava o problema (PARREIRAS, 2016).

As determinações do Código Florestal de preservação das matas ciliares são de extrema importância para a disponibilidade de água em quantidade e qualidade, no entanto estas áreas foram desmatadas, o que exemplifica a fragilidade da lei federal. Faltam programas e políticas públicas mais eficazes que garantam o cumprimento das exigências legais. Mas a legislação não será aplicável se não houver monitoramento e fiscalização para garantí-la.

Os impactos causados pelas atividades antrópicas no meio ambiente devem ser compensados com ações ambientais que garantam a sustentabilidade, de forma a não causar desequilíbrio ambiental, como apontado por Braga et al. (2012). Restrições e compensações podem ser utilizadas para diversas ações antrópicas que afetam o meio ambiente, como por exemplo para obras de infraestrutura na zona rural e para loteamentos na zona urbana.

Mesmo sendo mata e água inseparáveis, como observado por Graziano Neto (2009), ainda há carência de estudos de quantificação desta relação. Não se observa na literatura científica estudos que apontem de forma precisa a relação da quantidade e qualidade da água com a quantidade de vegetação nativa nas margens dos recursos hídricos.

Utilizando os resultados de Lacerda et al. (2009) ao nosso caso, APPs ao longo do rio Paraíba do Sul em Campos dos Goytacazes, podemos fazer um cálculo estimando o impacto do desmatamento em relação a captura e armazenamento do CO2-equivalente. Assim, se uma árvore captura e armazena 7,0 kg de CO2-equivalente em 1(um) ano, em 1(um) hectare (ha) com 2.500 árvores plantadas a quantidade de CO2-equivalente corresponde a 17.500,0 kg por ano. Portanto, nossa área de estudo, que apresenta 23.469.230,00 $\mathrm{m}^{2}$ ou 2.346,92 (ha) de área desmatada, poderá capturar aproximadamente $41.071 .100,0 \mathrm{~kg}$ de $\mathrm{CO} 2$-equivalente ao ano e $821.422 .000,0 \mathrm{~kg}(821.422 \mathrm{t})$ no período de 20 anos.

O conflito entre as atividades agropecuárias e as necessidades ambientais regulamentadas em lei tem sido constante ao longo do tempo, assim, é necessário que se

Persp. Online: exatas \& eng., Campos dos Goytacazes, 28 (10) $54-68$ - 2020

https://ojs3.perspectivasonline.com.br/ 
busquem medidas sustentáveis para a solução deste problema, visto que a falta de vegetação prejudica a disponibilidade de água em quantidade e qualidade, e consequentemente prejudicam as atividades econômicas e as condições de habitabilidade.

\section{CONCLUSÕES}

Esta pesquisa disponibiliza informações que podem contribuir com a preservação das matas ciliares como determina a legislação, contribuir com o planejamento e a gestão de recursos hídricos, a disponibilidade de água em quantidade e qualidade e o acesso aos diferentes usos da água. Destaca-se a importância da fiscalização no processo de preservação ambiental.

Verificou-se no estudo um grande distanciamento da quantidade de mata ciliar existente nas margens do rio Paraíba do Sul no município de Campos dos Goytacazes (apenas $9,20 \%$ ), e a quantidade exigida pela lei federal. Será importante o reflorestamento destas áreas desmatadas, especialmente com a utilização de espécies nativas (Mata Atlântica), que são mais adequadas à recuperação ambiental na região (flora, fauna, ar, água, solo). Este reflorestamento irá aumentar significativamente a captura e armazenamento de $\mathrm{CO} 2$ presente na atmosfera.

Considerando a difícil situação dos produtores rurais brasileiros, em que existe carência técnica e financeira, é necessário maior apoio das instituições governamentais para viabilizar um processo de produção mais sustentável, em que é preciso mais incentivos fiscais, programas de apoio financeiro para a preservação ambiental, monitoramento dos recursos ambientais, maior aproximação das universidades com suas pesquisas em apoio ao produtor, certificações ambientais, pesquisas para maior produtividade agropecuária em áreas de menor porte, difusão de ICMS ecológico e outros incentivos fiscais. Desta forma, podemse preservar as áreas de APPs sem comprometer a produção de alimentos, e a preservação dos recursos ambientais.

Contudo, recomenda-se que outros estudos sejam realizados para a quantificação da relação entre floresta e recursos hídricos, de forma a especificar, por exemplo, quanto um hectare (ha) de Mata Atlântica contribui com a disponibilidade de água em quantidade de metros cúbicos, e quanto este hectare contribui para melhorar a qualidade da água em diminuição de contaminantes e poluentes.

\section{REFERÊNCIAS}

ALVES, M.G.; COSTA, A.N.; POLIVANOV, H.; JUNIOR, G.C.S.; COSTA, M.C.O. Qualidade das águas de poços rasos provenientes de áreas urbanas e rurais de Campos dos Goytacazes-RJ. Revista Águas Subterrâneas, 2010. Disponível em: https://aguassubterraneas.abas.org/asubterraneas/article/view/22944/15081. Acesso em: 24.03.2020.

ARAUJO, R. S; ALVES, M.G; CONDESSO DE MELO, M. T.; CHRISPIM, Z.M.P.; MENDES, M. P; SILVA JÚNIOR, G.C. Water resource management: A comparative evaluation of Brazil, Rio de Janeiro, the European Union, and Portugal. Science of the Total Environment, v. 511, p. 815-828, 2015. DOI: j.scitotenv.2014.11.098.

Persp. Online: exatas \& eng., Campos dos Goytacazes, 28 (10) $54-68-2020$ 
ARAÚJO, R.S; PINHEIRO, J.B.; NUMES, I.N.; RANGEL, C.F.R.; CHRISPIM, Z.M.P. Execução de plano diretor: o caso de Campos dos Goytacazes 2008-2018. Pespectivas Online: Humanas e Sociais Aplicadas, v.9, n.26, p.141-162, 2019. DOI: $10.25242 / 8876926201897$

BRAGA, B., HESPANHOL, I., CONEJO, J.G.L., MIERZWA, J.C., BARROS, M.T.L., SPENCER, M., PORTO, M., NUCCI, N., NUESA, J., e EIGER, S. Introdução à engenharia ambiental. 2. ed., $9^{a}$ Reimpressão. São Paulo: Pearson Prentice Hall, 2012. ISBN: 978-857605-041-4.

BRASIL. Lei No 12.651, de 25 de maio de 2012. Código Florestal Brasileiro. Disponível em: http://www.jusbrasil.com. br/legislacao/1032082/lei-12651-12. Acesso: 22/04/19.

CAMPOS DOS GOYTACAZES. Lei Complentar $\mathbf{n}^{\mathbf{0}} \mathbf{0 0 1 5}$, de 07 de janeiro de 2020. Institui o Plano Diretor do Município de Campos dos Goytacazes e dá outras providências. Campos dos Goytacazes: Câmara Municipal, 2020.

CASTRO, D.; MELLO, R.S.P.; POESTER, G.C. (Org.). Práticas para restauração da mata ciliar. Porto Alegre: Catarse - Coletivo de Comunicação, 2012.

CHRISPIM, Z.M.P. Análise da vulnerabilidade e caracterização hidrogeoquímica dos aquíferos livres rasos da parte emersa da bacia sedimentar de Campos. Tese (Doutorado em Engenharia Civil) - Universidade Estadual do Norte Fluminense Darcy Ribeiro - UENF, CCT, LECIV. Campos dos Goytacazes: 2016.

CHRISPIM, Z.M.P.; RAMOS, I.; FERREIRA, H.G.; ALVES, M.G. Análise da vulnerabilidade dos aquíferos rasos do Município de Campos dos Goytacazes/RJ através da metodologia GOD. Revista Perspectivas Online: Exatas e Engenharias - Anais do VI CICC, V. 08, N 22, Suplemento, 2018.

EEA - EUROPEAN ENVIRONMENT AGENCY. Forest dynamics in Europe and their ecological consequences. Published 27 Nov. 2018. Disponível em: https://www.eea.europa.eu/themes/biodiversity/forests. Acesso em: 07/06/2020.

GRAZIANO NETO, F. Apresentação. In: Cadernos da mata ciliar. Secretaria de Estado do Meio Ambiente, Departamento de Proteção da Biodiversidade. $N^{\circ} 1$ (2009). São Paulo: SMA, 2009.

LACERDA, J. S.; COUTO, H. T. Z.; HIROTA, M.M.; PASISHNYK, N.; POLIZEL, J. L. Estimativa da biomassa e carbono em áreas restauradas com plantio de essências nativas. METRVM, n.5/novembro/2009. ESALQ, Universidade de São Paulo, Piracicaba, SP Disponível em: http://cmq.esalq.usp.br/wiki/doku.php?id=publico:metrvm:start. Acesso em: 05/06/2020.

LAWRENCE, Deborah; VANDECAR, Karen. Effects of tropical deforestation on climate and agriculture. Nature climate change, v. 5, n. 1, p. 27-36, 2015. DOI: 10.1038/NCLIMATE2430

MATHER, A. S. The transition from deforestation to reforestation in Europe. In: ANGELSEN, A.; KAIMOWITZ, D. (eds). Agricultural technologies and tropical

Persp. Online: exatas \& eng., Campos dos Goytacazes, 28 (10) $54-68$ - 2020

https://ojs3.perspectivasonline.com.br/ 
deforestation. CAB International, Wallingford, United Kingdom, 2001.

MEDEIROS, J.D. A demarcação de áreas de preservação permanente ao longo dos rios. Biotemas, v. 26, n. 2, p. 261-270, 2013. DOI: 10.5007/2175-7925.2013v26n2p261.

MOREIRA, G. Dia Mundial da Água 2019 - "Não deixar ninguém para trás". Disponível em: https://nacoesunidas.org/artigo-dia-mundial-da-agua-2019-nao-deixar-ninguem-para-tras/ Acesso: 22/04/2019.

MOSS, M. Água e floresta: um círculo virtuoso de cooperação. In: Água e cooperação: reflexões, experiências e alianças em favor da vida. Sérgio Ribeiro, Vera Catalão e Bené Fonteles (organizadores); [tradução oller Ibañez]. Brasília: Ararazul - Organização para a Paz Mundial, 2014.

PARREIRAS, H. Devastação das matas ciliares em Minas é ameaça de proporções desconhecidas. Jornal Estado de Minas Gerais. Belo Horizonte, 05/06/2016. Disponível em: https://www.em.com.br/app/noticia/gerais/2016/06/05/interna_gerais,769450/devastacaodas-matas-ciliares-em-minas-e-ameaca-de-proporcoes-desconhe.shtml. Acesso em: 04/06/2020.

RIEBEEK, H. The carbon cycle. Earth Observatory - NASA, June 16, 2011. Disponível em: https://earthobservatory.nasa.gov/features/CarbonCycle. Acesso em: 05/06/2020.

SILVA, José Afonso da. Direito urbanístico brasileiro. 7. ed., 2. tir. São Paulo: Malheiros Editores, 2015.

SOUZA, F.P.; PERTEL, M. Complexidades para a aplicação dos aspectos normativos para a gestão de recursos hídricos no Brasil. Perspectivas Online: Exatas \& Engenharia, v.10, n.27, p.70 - 82, 2020. DOI: 10.25242/885X102720201747

ZAKIA, M. J. B. Identificação e caracterização da zona ripária em uma subbacia experimental: implicações no manejo de bacias hidrográficas e na recomposição de florestas. Tese (Doutorado em Ciências da Engenharia Ambiental) - Universidade Paulista, São Carlos SP. 1998. 